\title{
Variable Morphology of the Hyoid Bone in Anatolian Population: Clinical Implications - A Cadaveric Study
}

\author{
Morfología Variable del Hueso Hioides en una Población de Anatolia: \\ Consecuencias Clínicas - Un Estudio Cadavérico
}

Cem Kopuz* \& Gürsel Ortug**

KOPUZ, C. \& ORTUG, G. Variable morphology of the hyoid bone in Anatolian population: Clinical implications- A cadaveric study. Int. J. Morphol., 34(4):1396-1403, 2016.

SUMMARY: The variations of the hyoid bone has a great significance for surgical procedures of neck region, and in forensic medicine for evidence of strangulation or hanging, which causes fractures. The aim of this study was to investigate the morphological and morphometrical variations of the hyoid bone in Anatolian population. A total of 60 adult larynx specimens ( 46 male, 14 female) were dissected to identify morphological and morphometrical variations of hyoid. The infrahyoid muscles and thyrohyoid membrane were cut and ligamentous structures of bone were removed. The variations of shape of the hyoid were classified into six types: A(U-shaped) hyoid bone observed in $31.7 \%$ (19 bones), a horseshoe-H-type in $10 \%$ (6 bones), a B-type hyoid in $31.7 \%$ (19 bones), a D-type hyoid in \% 15 ( 9 bones), a V-type bone in $\% 5$ ( 3 bones) and HK-type bone in $6.7 \%$ (4 bones) of all necks. The breadth, width and major transverse axis were approximately measured as $40.4 \mathrm{~mm}, 28.4 \mathrm{~mm}$ and $33.5 \mathrm{~mm}$, repectively. It has been found that the hyoid bones of Anatolian population had morphologically important differences than in other populations. To understand the anatomical variations and measurements of this bone is of valuable importance with regard to clinical practice and forensic medicine.

KEY WORDS: Hyoid bone; Shape; Variation; Morphometry; Embryology.

\section{INTRODUCTION}

Variations of some metric characteristics of the hyoid bone have been reported in western populations (Chang 1967; Kindschuh et al., 2012; Leksan et al., 2005; Miller et al., 1998; Martinez et al., 2008). Except for Indian and Korean populations (Kindschuh et al., 2010;Kim et al., 2006), little attention has been paid to this anatomic issue in the eastern populations. The standard anatomical and clinical textbooks provide only basic information about this bone (Standring 2008; Woodson 2006) and describe it as symmetric or U-shaped. On the other hand, relatively fewer studies have been focused on variants of the shape of hyoid Kim et al. and Koebke \& Saternus (1979) have described its shape as symmetric or asymmetric, parabolic or hyperbolic, respectively. Another classification which includes five types (B,D,H,U, and V types) has been done by Papadopoulos et al., (1989). No studies have been reported in Anatolian.

Because of its anatomic position and physical rigidity and variations of its shape, it has been stated that the hyoid bone becomes a prime indicator in strangulation or hanging or cervical trauma cases and it also has forensic significance (Kindschuh et al., 2012; Kindschuh et al., 2010; Kim et al.; Leksan et al.; Mukhopadhyay, 2010; Pollanen \& Chiasson,1996; Pollanen \& Ubelaker, 1997). Its fractures could depend on the shape and calcification of the bone (Cerny,1990; Kim et al.; Leksan et al.; Miller et al.,). They usually occur in the mean or in the posterior third of the greater horn of the hyoid in older individuals (Porrath, 1969). Hyoid bone abnormalities or malformations can be seen in different clinical conditions such as Pierre Robin sequence and cleft lip and palate, enlargement greater cornu of thyroid cartilage (Mukhopadhyay; Pollanen, 1997). Some authors blame anatomical malformations of the hyoid bone for discomfort in the region of the hyoid bone at rest or when turning the head (Mori et al.,1994).

The anatomic abnormalities and variations of the bone structures of the neck have recently become significant because of the new imaging techniques such as spiral computed tomographic scan with 3-dimensional

\footnotetext{
* Ondokuz Mayıs University, Medical Faculty, Department of Anatomy, Samsun -Turkey.

** Bahçesehir University, Medical Faculty, Department of Anatomy, Istanbul -Turkey.
} 
reconstruction and magnetic resonance imaging. Also the investigation of these variants is important in order to define the morphologic features for clinical dignosis and for surgical precedures. The aim of this study is to determine the morphological features of the hyoid bone in Anatolian population and contribute additional data to the literature.

\section{MATERIAL AND METHOD}

The present study was carried out on 60 cadaver specimens (46 male, 14 female) who had no previous surgical procedures in the laryngeal area. All of the specimens were aged between 19-80. They had been stored in $10 \%$ buffered formalin. The specimens which have laryngeal cartilages, thyroid gland, infrahyoid muscles and thyrohyoid membrane were dissected. First, infrahyoid muscles and thyrohyoid membrane were cut following from the down to $1 \mathrm{~cm}$ of hyoid bone, then muscular and ligamentous structures of bone were removed. All measurements of the bones were performed using a standart digital caliper and keeping the bone on flat surface in anatomical positions.

The shapes of hyoid bones were macroscopically noted and classified according to the system described by Papadopoulos et al. According to this system, when the anterior part of bone is composed of a half circle and the diameter of the half circle and posterior transverse diameters is approximately the same, the bone is said to be of the" $U$ Type; when the diameter of a half circle anteriorly is longer than distance between the greater horns, the bone is classified as the "horseshoe-H -Type"; B -Type resembles a transverse section of a boat and its diameter coincides with the major transverse axis. When its anterior part is a half circle, posteriorly one or both greater horns deviate to one or to the other side, bone is said to be of the "deviating-D-Type", when it is triangular shape or resembling the letter $\mathrm{V}$, it is said to be of the "V-Type". When its right and left greater horns do not lie in same plane and left cornu is curved medially, it is named to be of the HK-Type (Figs. 1, 2 and 3).

For further subdivisions of the main classification were determined as symmetric and asymmetric. A bone is symmetric if the middle of all its transverse diameters falls on the sagittal axis, otherwise it is asymmetric, deviating to one of the sides (right or left).

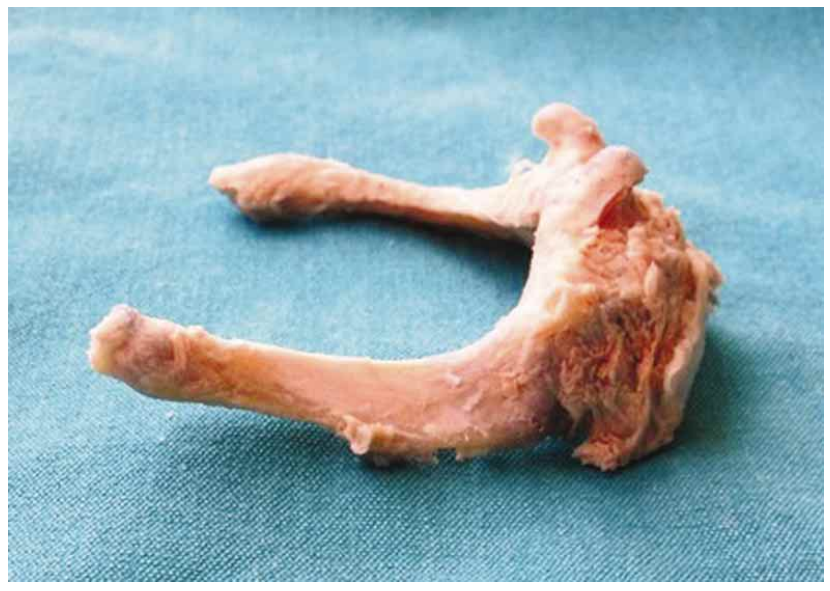

Fig. 2. Asymmetrical form of hyoid bone (D-Type).

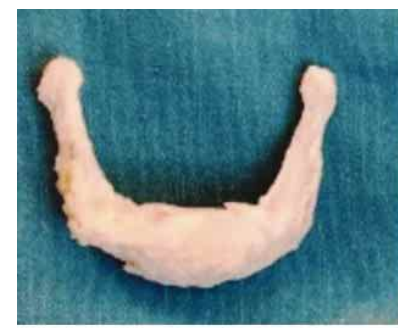

a

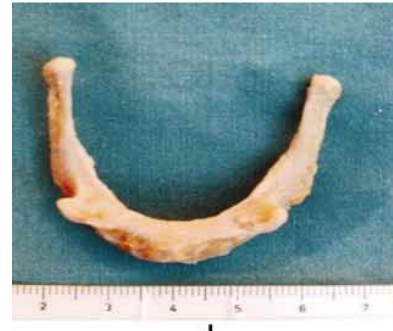

d

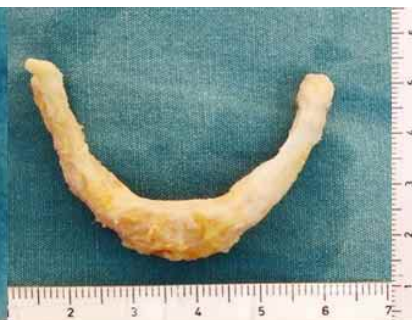

b

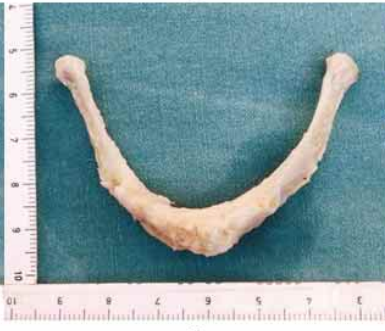

e

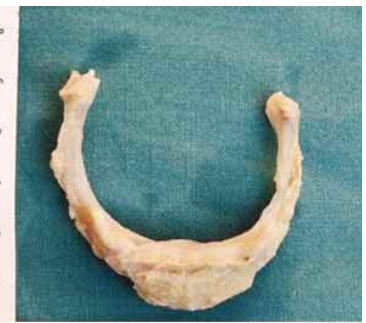

C

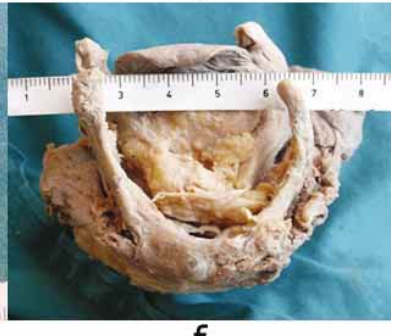

f

Fig. 1. Types of classification of hyoid bone according to their shape. a. U-Type; b. Horseshoe - H-Type; c. B-Type; d. D-Type; e. V-Type; f.HK-Type. 
The following osteometric measurements were taken (also see Fig.4).

a) Breadth or width of hyoid: distance between the distal ends of the greater cornu.

b) Length: distance separating a line through the distal ends of the greater cornu and the center of the hyoid body.

c) Major transverse axis: distance between the interior contours of the greater horns;

d) Length of body: distance between both body-lesser cornu junctions.

e) Length of left cornu: distance from the junction of lesser cornu and body to the tip of left greater cornu.

f) Length of right cornu: distances from the junction of lesser cornu and body to the tip of greater cornu.

g) Maximum height of the hyoid body: taken from the most superiorly and inferiorly projecting points.

h) Total left hyoid length: distance from superior end of left greater cornu to inferior margin of anterior surface of body.

i) Total right hyoid length: distance from superior ends of right greater cornu to inferior margin of anterior surface of body.

Data were analyzed statistically using analysis of variance (Anovatest), t-test, Tukey-test and $\mathrm{x}^{2}$ test.

\section{RESULTS}

The morphologic types of hyoid bone were determined. Of these $\mathrm{U}, \mathrm{H}$ (horse-shoe), B, D (deviating type) and V types of the Papadopoulos (4) system and HK-type could be macroscopically identified (Figs 1, 2 and 3). The HKtype had macroscopically a transitional form between D-type and H-type. One of its cornu majus shows a hook form, while the other one was flat. On the other hand, it had asymmetrical form as the D-type (Figs 1 and 2).

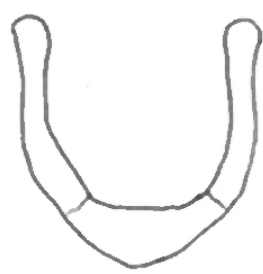

Type-U

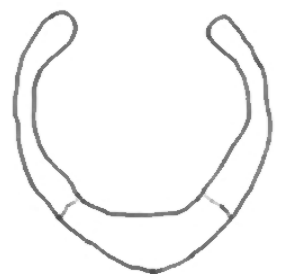

Type-H

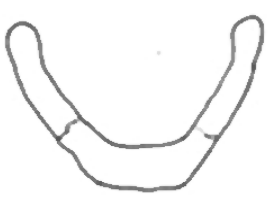

Type-B
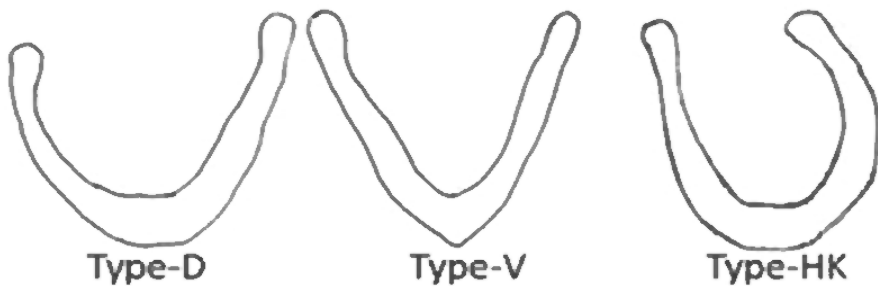

Fig. 3. Schematic diagram of hyoid types

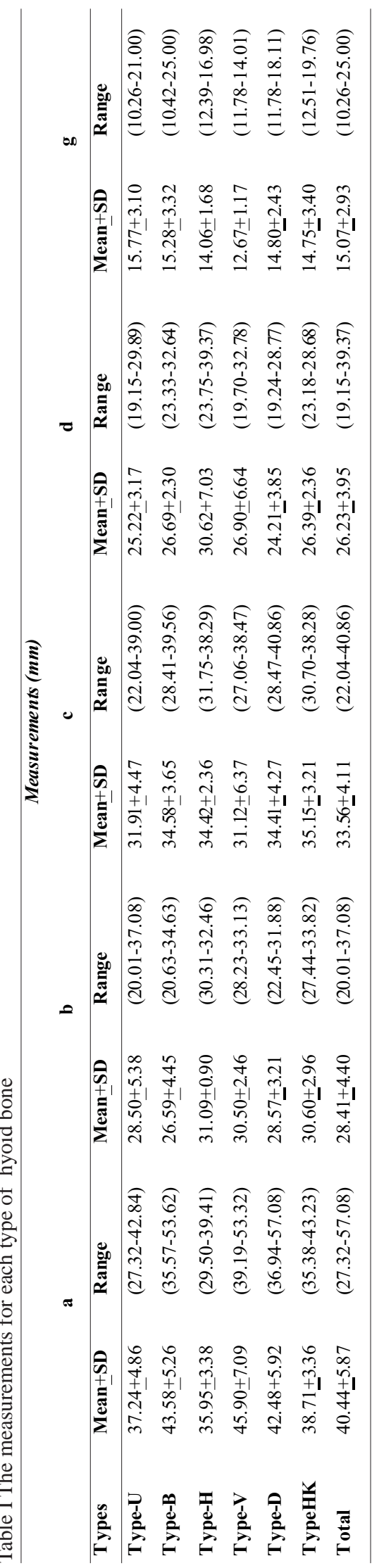




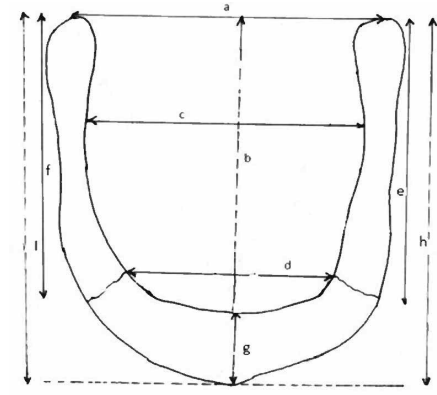

Fig. 4. Osteometric measurements. a. Breadth or width of hyoid; $b$. Length; c. Major transverse axis; d. Length of body; e. Length of left cornu; f. Length of right cornu; $\mathrm{g}$. Maximum height of the hyoid body; h. Total left hyoid length; i) Total right hyoid length.

Table II. Averages of osteometric measurements of hyoid bone.

\begin{tabular}{cccc}
\hline $\begin{array}{c}\text { Measurement } \\
(\mathbf{m m})\end{array}$ & Male $(\mathbf{n}=\mathbf{4 6})$ & Female $(\mathbf{n}=\mathbf{1 4})$ & Total $(\mathbf{n}=\mathbf{6 0})$ \\
\hline$* \boldsymbol{a}$ & $41.31 \pm 6.03$ & $37.56 \pm 4,36$ & $40.44 \pm 5.87$ \\
$\boldsymbol{b}$ & $28.30+4.34$ & $28.76+4,73$ & $28.41+4.40$ \\
$\boldsymbol{c}$ & $34.07+4.19$ & $31.88+3,46$ & $33.56+4.11$ \\
$\boldsymbol{d}$ & $26.52+4.22$ & $25.28+2,84$ & $26.23+3.95$ \\
$\boldsymbol{e}$ & $25.44+4.50$ & $24.79+4,11$ & $25.29+4.39$ \\
$\boldsymbol{f}$ & $25.61 \pm 4.53$ & $24.79 \pm 4,11$ & $25.42 \pm 4.42$ \\
$\boldsymbol{g}$ & $15.35+2.85$ & $14.16+3,08$ & $15.07+2.93$ \\
$\boldsymbol{h}$ & $39.45 \pm 4.71$ & $38.98 \pm 6,54$ & $39.34 \pm 5.13$ \\
$\boldsymbol{l}$ & $39.33+4.55$ & $38.98+6,54$ & $39.25+5.02$ \\
\hline
\end{tabular}

$*_{t}=2.157, P<0.05$

Table III. Frequency of shapes of hyoid bone for sex.

\begin{tabular}{|c|c|c|c|c|c|c|c|c|c|c|c|c|c|c|}
\hline \multicolumn{15}{|c|}{ Hyoid bone types } \\
\hline & \multicolumn{2}{|c|}{ Type-U } & \multicolumn{2}{|c|}{ Туре-В } & \multicolumn{2}{|c|}{ Туре-Н } & \multicolumn{2}{|c|}{ Type-V } & \multicolumn{2}{|c|}{ Type-D } & \multicolumn{2}{|c|}{ Туре-НК } & \multicolumn{2}{|c|}{ Total } \\
\hline Sex* & & & & & & & & & & & & & & \\
\hline Male & 12 & 26.1 & 15 & 32.6 & 5 & 11.0 & 1 & 2.2 & 9 & 19.6 & 4 & 8.7 & 46 & 100 \\
\hline Female & 7 & 5.0 & 4 & 28.6 & 1 & 7.1 & 2 & 14.3 & - & - & - & - & 14 & 100 \\
\hline Total & 19 & 31.7 & 19 & 31.7 & 6 & 10.0 & 3 & 5.0 & 9 & 15.0 & 4 & 6.6 & 60 & 100 \\
\hline
\end{tabular}

$\mathrm{X} 2=9.24, \mathrm{P}>0.05$

Table IV. Frequency of hyoid bone shapes for various age groups.

\begin{tabular}{|c|c|c|c|c|c|c|c|c|c|c|c|c|c|c|}
\hline \multicolumn{15}{|c|}{ Hyoid bone types } \\
\hline & \multicolumn{2}{|c|}{ Type-U } & \multicolumn{2}{|c|}{ Туре-В } & \multirow{2}{*}{\multicolumn{2}{|c|}{$\begin{array}{c}\text { Type-H } \\
\text { No. } \%\end{array}$}} & \multicolumn{2}{|c|}{ Type-V } & \multicolumn{2}{|c|}{ Type-D } & \multicolumn{2}{|c|}{ Туре-НК } & \multicolumn{2}{|c|}{ Total } \\
\hline Age & & & & & & & & & & & & & & \\
\hline$<30$ & 7 & 36.8 & 7 & 36.8 & 2 & 10.5 & 1 & 5.3 & 1 & 5.3 & 1 & 5.3 & 19 & 31.7 \\
\hline $31-50$ & 6 & 28.6 & 3 & 14.3 & 3 & 14.3 & 1 & 4.8 & 6 & 28.6 & 2 & 9.5 & 21 & 35.0 \\
\hline $51-70$ & 5 & 35.7 & 5 & 35.7 & 1 & 7.1 & 1 & 7.1 & 2 & 14.3 & 0 & - & 14 & 23.3 \\
\hline $70<$ & 1 & 16.7 & 4 & 66.7 & - & - & - & - & - & - & 1 & 16.7 & 6 & 10.0 \\
\hline Total & 19 & 31.7 & 19 & 31.7 & 6 & 10.0 & 3 & 5.0 & 9 & 15.0 & 4 & 6.7 & 60 & 100 \\
\hline
\end{tabular}




\section{DISCUSSION}

Dissections have shown that the six main forms of hyoid bone can be macroscopically identified in the adults in Anatolian population: $\mathrm{U}, \mathrm{H}, \mathrm{B}, \mathrm{D}, \mathrm{V}$ and HK types. This is supported by the statistically significant differences of the proximal and distal transverse diameters (a and $\mathrm{d}$ measurements) between $\mathrm{B}$ and $\mathrm{U}$, and $\mathrm{B}$ and $\mathrm{H}$ types. As mentioned by Papadopoulos et al., there is a clear distinction between $\mathrm{H}$ and U-types of the classical description, which together cover only $42 \%$ of the population. Four other types, $\mathrm{B}, \mathrm{D}, \mathrm{V}$ and $\mathrm{HK}$ types not specially mentioned in the texbooks, cover the remaining of $58 \%$, to of which B type is most common in the overall frequency.

In the other articles, variations of hyoid shape and its morphometry were shown in Tables V-VI. reported Papadopoulos et al. have reported the incidence of the "U,H,B,D and V -types" of the hyoid as $18.4 \%, 21.1 \%$, $26.3 \%, 28.9 \%$ and $5.3 \%$ respectively. They also had classified the hyoid bones as asymmetrical (47.4\%) and symmetrical $(52.6 \%)$. Their H, D and U types were asymmetric and $\mathrm{B}$ and $\mathrm{V}$ shaped bones did not show asymmetry.

In classification of Koebke \& Saternus (1979), parabolic type (40.9\%) belong to our B and V-type (36.7), their horseshoe (Hufeisen) type (13.1\%) to our H-type(10 $\%)$, their hyperbolic type (35\%) to our U-type (35\%) and their asymmetric type (11\%) to our D-type (15\%). Pollanen \& Ubelaker have classified the hyoids as hyperbolic (Ushaped) (55\%) and parabolic (V-Shaped) (45\%) according to length and width of bone. Leksan et al. have considered the types of hyoid bone as symmetrical (85.7\%) and asymmetrical (15.3\%); Although their symmetrical type has included U (51.6\%) and V shaped hyoids (48.4\%), asymmetrical type has not been classified according to shapes of hyoid bone.

In Croatia population, it was found that incidences of symmetric and asymmetric hyoids as $85.7 \%$ and $15.3 \%$, respectively. Authors have determined U (31\%) and V shaped bones (29\%) as symmetrical, and the others as asymmetrical (Leksan et al., 2005). In their study the incidence of asymmetric bones of males was lower than females (in males $5.7 \%$, in females $22.8 \%$ ). In Indian population incidences of symmetrical and asymmetrical hyoids were found as $93.1 \%$ and $6.9 \%$, respectively (Mukhopadhyay 2006).

In the current investigation, other notable observation was HK- shaped bone which its right and left greater horns do not lie in the same plane and left cornu is curved medially. We have not seen similar finding in any other studies. Only Klinefelter (1952) had found a case which right and left cornu majus did not lie in the same plane and the left greater cornu was angulated downward and backward. In our series, $\mathrm{U}$ and $\mathrm{B}$ types were more and $\mathrm{V}$ type less common with incidences of $31.7 \%, 31.7 \%$, and $5 \%$, respectively (Table V).

Leksan et al., (2005) and Pollanen and Ubelaker found the U-type hyoid, and Koebke \& Saternus B-type hyoid more common and Papadopoulos et al. D-type hyoid, Martinez et al. V-type hyoid (Table V). Our findings correspond those of Leksan and Koebke. In contrast, it is not similar to those of Papadopoulos and Martinez. The minority of incidence of V-type hyoid show similarity between Anatolian and Greek populations. In the past, immigrations between two society might cause this condition. While in Greek population there was no significant difference between incidences of symmetric and asymmetric hyoids, in other populations, incidence of symmetrical hyoids was more higher than asymmetric hyoids.

"A, c and g" measurements showed statistically significant differences between Africans and Europeans. It also has been determined that above measurements were larger in male hyoids than female hyoids (Kindschuh et al., 2012).This is consonance with our study on Anatolian population. As seen in Table VI, different authors have found the dimensions of hyoid to be very similar. An exception was the paper by Kim et al. who noted a hyoid width of $37.2 \mathrm{~mm}$. We found the width of hyoid as slightly

Table V. Percentages of shapes of hyoid bone compared with the previous studies

\begin{tabular}{lccccccccc}
\hline \multicolumn{1}{c}{ Study } & N & Sy m(\%) & Asym.(\%) & U(\%) & H(\%) & B(\%) & D(\%) & V(\%) & HK(\%) \\
\hline Papadapoulos (1989) & 76 & 52.6 & 47.4 & 18.4 & 21.1 & 26.3 & 28.9 & 5.3 & - \\
Koebke \& Saternus (1979) & 504 & 89.0 & 11.0 & 35.0 & 13.1 & 40.9 & 11.1 & $(40.9)$ & - \\
Pollanen et al. (1997) & 100 & - & - & 55.0 & - & 45.0 & - & $(45.0)$ & - \\
Leksan et al. (2004) & 70 & 85.7 & 14.3 & 51.6 & - & 48.4 & - & $(48.4)$ & - \\
Mukhopadhyay (2010) & 144 & 93.1 & 6.9 & - & - & - & - & - & - \\
Martinez et al. (2008) & 17 & - & - & - & - & & 11.8 & 11.8 & - \\
Present study (2015) & 60 & 78.3 & 21.7 & 31.7 & 10.0 & 31.7 & 15.0 & 5.0 & 6.7 \\
\hline
\end{tabular}


Table VI. Measurements of the hyoid bone compared with previous studies

\begin{tabular}{|c|c|c|c|c|c|c|c|c|c|c|}
\hline \multirow[t]{2}{*}{ Study } & \multirow[t]{2}{*}{$\mathbf{N}$} & \multirow[t]{2}{*}{ Specimen } & \multicolumn{8}{|c|}{ Measurements (mm) } \\
\hline & & & $\mathbf{a}$ & b & c & d & e & f & $\mathbf{k}$ & I \\
\hline Chang (1967) & 100 & Cadaver (Korean) & 39.4 & - & - & - & 31.3 & 31.2 & - & - \\
\hline Miller et. al. (1998) & 315 & Radiograph (North American) & 39.9 & 26.3 & - & 20.3 & 29.5 & 27.9 & - & - \\
\hline Leksan et. al. (2005) & 70 & Dry bone (Croatia) & 43.2 & 38.8 & - & 30.0 & 26.6 & 26.8 & 15.8 & - \\
\hline Kim et. al. (2006) & 85 & Cadaver (Korean) & 37.2 & 29.2 & 20.3 & - & 30.7 & 31.2 & 7.4 & - \\
\hline Martinez et. al. ((2008) & 60 & Dry bone (Afrc. Amr. Eur.) & - & - & - & 22.3 & - & - & 11.7 & - \\
\hline Mukhopadhyay (2010) & 144 & Autopsy (India) & 38.9 & 25.8 & - & - & 26.7 & - & - & - \\
\hline Kindschuh et. al. (2012) & 100 & Dry bone (African) & 39.2 & - & 38.9 & 21.3 & 28.8 & - & 11.3 & 35.7 \\
\hline Kindschuh et. al. (2012) & 100 & Dry bone (European) & 43.4 & - & 42.5 & 23.2 & 29.6 & - & 11.3 & 35.0 \\
\hline Present study (2015) & 60 & Cadaver (Anatolian) & 40.4 & 28.4 & 33.5 & 26.3 & 25.2 & 25.4 & 15.1 & 39.3 \\
\hline
\end{tabular}

higher than other populations and lower than European and Croatia populations. In our study, it was observed that the length of hyoid was higher than that of Croatia population. On major transverse axis "c" value, our finding is higher than that of Korean population and lower than those of African and European population. In the present study "d, e, f and g" measurements of Anatolian population are principally different from other populations.

It was observed that there was no significant difference between lengths of the left and right cornua or majority of them were symmetrical (Leksan et al.; papadopoulos et al.; Kim et al.; Mukhopadhyay; Pollanen and Ubelaker; Miller et al.; Koebke and Saternus). Our results correspond to the findings in other populations. In our study, the length and maximum height of body were found to be higher than other populations except for Croatia population, which may be assocated with anatomical differences between different ethnic groups or geographical regions. In a case presented by Sittel et al. (1998), right greater cornu of the hyoid bone was noted to be elongated and was blocked by the lateral process of the cervical vertebra. In this patient, there is a discomfort in the region of the hyoid bone at rest or when turning the head. To understand the underlying pathological condition, the hyoid morphology should be evaluated by clinician. From the point of view of this, lengths of greater cornua consequently the shape of hyoid should be known.

In my opinion, the different activities of developmental genes may cause the clefting in mesenchyme of different parts of hyoid. On the other hand the differences on regulation of differentation of developmental genes may cause the difference of development of hyoid body and its major and minor cornua stage by stage, consequently, the different shapes of hyoid may appear. Additionally, differences in suprahyoid musculature insertion may be the cause of different shapes of hyoid.
Endotracheal intubation is generally considered to be the contemporary method of securing an airway and assuring adequate ventilation. To determine accurate central positioning of the intubation guide surface, hyoid bone is a major anatomical landmark of neck . Its unskilled insertion can cause additional injuries, for example, to the front incisors Alexopoulos et al.,1983; Dhara, 2009). Sometimes the shape of the standard endotracheal tube can not conform to the anatomy of the airway and this inharmoniousness is probably the most injurious factor of tracheal intubation. In order to measure the tube recoil deformation pressure at different points of the airway, it is necessary to know the exact shape of the airway (Alexopoulos et al.). In our study, width of hyoid was found shorter in $\mathrm{H}$ - type than other types. This may cause the difficulties during intubation.

The most important lesions of the hyoid apparatus are the fractures with direct trauma due to an outside force and muscular fractures (Porrath). They are usually seen in the body or greater cornu of the hyoid and have a much higher prevalance in men than women (Dalati, 2005). The hyoid fractures due to inward compression such as manual strangulation, sudden hyperextension of the neck, anteroposterior compression such as hanging or direct blows to the neck and bullet wounds (Porrath), $34 \%$ of cases of manual strangulation have a fractured hyoid bone (Ubelaker, 1992). (Pollanen \& Chiasson (1996) have mentioned that the shape of hyoid and its rigidity was one of the important factors of hyoid fractures. However, they only determined two hyoid shapes as parabolic and hyperbolic. Our classification include six hyoid types which may be important in forensic medicine. It has been reported that cornu of fractured hyoid or length of hyoid were larger than those of unfractured hyoid bones (Pollanen \& Chiasson, 1996). In our study for cornua of $\mathrm{H}, \mathrm{V}$ and HK types of hyoid are longer than other types. Consequently they are more vulnerable or more predisposed to fracture. 
There has been an increasing number of reports of hyoid fractures occuring in high speed automobile and motorcycle accidents (Reimann). The etiology of a tear of fibrous junction of the greater cornua and the body with displacement is probably the sudden hyperextension and thrust that occured at the time of the accident with a muscular fracture resulting (Reimann,1961). This position also places many of the muscles attaching to the hyoid bone under tension, decreasing the mobility of the hyoid and thus its ability to absorbe forces (Porr et al., 2012). In this condition, the shape of hyoid especially V, H and HK- typed hyoids may be forceful on fracture because of reducing its ability to absorbe forces. The age depency of hyoid fracture correlated with the degree of ossification or fusion of the hyoid synchondros (Papadopoulos et al.; Pollanen \& Ubelaker, 1997; Pollanen \& Chiasson, 1996; Dalati). A rigid cornua is more likely to fracture than prior to fussion the elastic cartilaginous structure of the hyoid or applicable cornu (Dalati; Porr et al.).

\section{CONCLUSIONS}

This is the first reported morphological study on cadaveric hyoid bones from Anatolian population and it highlights individual and ethnic/racial variations. Our qualitative quantitative research on the morphological variability of hyoid bone provides precise well-sorted data about variations of morphometry and shape of hyoid bone in a Anatolian population to supplement the existing reports of its kind which will contribute to a thorough understanding of the human hyoid. Our new morphological observations in the Anatolian population may also be of interest to clinicians as well as anatomists. Knowledge of morphological variations of hyoid bone is essential for helping the clinician in the diagnosis and treatment of discomforts in the region of the neck and for surgical procedures .

KOPUZ, C. \& ORTUG, G. Morfología variable del hueso hioides en una población de Anatolia: consecuencias clínicas - Un estudio cadaverico. Int. J. Morphol., 34(4):1396-1403, 2016.

RESUMEN: Las variaciones del hueso hioides tiene un gran significado para los procedimientos quirúrgicos de la región del cuello, y en la medicina forense para la evidencia de estrangulación o ahorcamiento que causan fracturas. El objetivo de este estudio fue investigar las variaciones morfológicas y morfométricas del hueso hioides en una población de Anatolia. Un total de 60 muestras de laringe adultas (46 hombres, 14 mujeres) fueron disecadas para identificar las variaciones morfológicas y morfométricas del hueso hioides. Se seccionaron los músculos infrahioideos y la membrana tirohioidea, y fueron removidas las estructuras ligamentosas de los huesos. La forma del hioides se clasificó en seis tipos: a (forma de U) del hueso hioides observó en el 31,7 \% (19 huesos), forma de herradura hioides in $10 \%$ (6 huesos), hioides de tipo B en el 31,7 \% (19 huesos), tipo D hioides en $15 \%$ (9 huesos), un hueso de tipo V en \% 5 (3 huesos) y de tipo HK hueso en un 6,7 \% (4 huesos) de todos los cuellos. Se midió la amplitud, ancho y el eje transversal mayor de 40,4 mm, 28,4 mm y 33,5 mm. Determinamos que los huesos hioides de la población Anatolia tenían importantes diferencias morfológicas en comparacion a otras poblaciones. El conocimiento de las variaciones anatómicas y las mediciones de este hueso es importante con respecto a la práctica clínica y la medicina forense.

PALABRAS CLAVE: Hueso hioides; Forma; Variación; Morfometría; Embriología.

\section{REFERENCES}

Alexopoulos, C.; Larsson, S .G.; Lindholm, C.E. Anatomical shape of the airway. Acta Anaesthesiol. Scand., 27(3):185-92, 1983.

Cerny, S.K.M. Sex determination from the hyoid bone by means of discriminant analysis. Acta Univ. Palacki Olomuc Fac Med., 125:37-51, 1990.

Chang, H.S .Anatomical studies on the hyoid bone of Korean. Mod. Med., 6 (4):427-40, 1967.

Dalati, T. Isolated hyoid bone fracture. Review of an unusual entity. Int. J. Oral Maxillofac. Surg., 34(4):449-52, 2005.

Dhara, S.S. Retrograde tracheal intubation. Anaesthesia, 64(10):1094-104. 2009.

1402
Kim, D.I.; Lee, U.Y.; Park, D.K.; Kim,Y.S.; Han, K.H.; Kim, K.H. et al. Morphometrics of the hyoid bone for human sex determination from digital photographs. J. Forensic Sci.,51(5):979-84, 2006.

Kindschuh, S.C.; Dupras, T.L.; Cowgill, L.W. Exploring ancestral variation of the hyoid. J. Forensic Sci., 57(1): 41-6, 2012.

Kindschuh, S.C.; Dupras, T.L.; Cowgill, L.W. Determination of sex from the hyoid bone. Am. J. Physic. Anthropol., 143(2):279$84,2010$.

Klinefelter, E.W. The anomalous hyoid; review of the literature and report of a case. Radiology, 58(2):224-27, 1952. 
Koebke, J.; Saternus, K. Zur morphologie des adulten menschlichen Zungenbeins. Zeitschrift für Rechtsmedizin, 84:7-18, 1979.

Leksan, I.; Marcikic, M.; Nikolic, V.; Radic, R.; Selthofer, R. Morphological classification and sexual dimorphism of hyoid bone: New approach. Cell. Anthropol., 29(1):237-42, 2005.

Martinez, I.; Arsuaga, J.L.; Quam, R.; Carretero, J.M.; Gracia, A.; Rodriguez, L. Human hyoid bones from the middle Pleistocene site of the Sima de Los Huesos (Sierra de Atapuerca, Spain). J. Hum. Evolution, 54:118-24, 2008.

Miller, K.W.P.; Walker, P.L.; O'Halloran, R.L. Age and sex related variation in hyoid bone. J. Forensic Sci., 43(6):1138-43,1998.

Mori, H.; Nishimura, Y.; Satomi, F.; Mohri .D.; Komoi. T. Reconsideration on the hyoid syndrome. Otolaryngol. Head Neck Surg., 110:324-29, 1994.

Mukhopadhyay, P. P. Morphometric features and sexual dimorphism of adult hyoid bone: A population specific study with forensic implications. J. Forensic Leg. Med., 17(6):321$24,2010$.

Papadopoulos, N.; Likyaki-Anastopoulou, G.; Alvanidou, E. The shape and size of the human hyoid bone and a proposal for an alternative classification. J. Anat., 163:249-60, 1989.

Pollanen, M. S.; Ubelaker, D. H. Forensic significance of the polymorphism of hyoid bone shape. J. Forensic Sci., 42(5):89092, 1997.

Pollanen, M. S. \& Chiasson, D. A. Fracture of the hyoid bone in strangulation: comparison of fractured and unfractured hyoids from victims of strangulation. J. Forensic Sci., 41(1):110-3, 1996.

Porr, J,; Laframboise, M.; Kazemi, M. Traumatic hyoid bone fracture - a case report and review of the literature. J. Can. Chiropr. Assoc., 56(4):269-74, 2012.

Porrath, S. Roentgenologic considerations of the hyoid appratus. Am. J. Roentgenol. Radium Ther. Nucl. Med., 105(1):6373,1969 .

Reimann, W. Fractures of the hyoid bone and thyroid cartilage in traffic accidents. Dtsch. Z. Gesamte Gerichtl. Med., 52:70-5, 1961 .

Sittel, C.; Brochhagen, H.G.; Eckel, H.E.; Michel, O. Hyoid bone malformation confirmed by 3 -dimensional computed tomography. Acta Otolaryngol. Head Neck Surg., 124(7):799801, 1998.

Standring, S. Gray'sAnatomy: The Anatomical Basis of Clinical Practice. 40th ed. London: Churchill \& Livingstone, pp 397,405,503,573, 2008.
Ubelaker, D.H. Hyoid fracture and strangulation. J. Forensic Sci., 37(5):1216-22, 1992.

Woodson, G.E. Head and Neck Surgery- Otolaryngology .Upper airway anatomy and function. $4^{\text {th }}$ ed. New York: Lippincott and Williams\&Wilkins, pp 693-702, 2006.

Corresponding author:

Prof. Dr. Cem Kopuz

Ondokuzmayıs University

Medical Faculty

Department of Anatomy

KörfezMah. Atatürk Bulv. N0:112

Samsun

TURKEY

Email:drkopuz@gmail.com

Received: 03-05-2016

Accepted: 19-08-2016 